\title{
Late gadolinium enhancement score (LGE-Score) for prediction of extensive late gadolinium enhancement in hypertrophic cardiomyopathy
}

\author{
Raymond H Chan ${ }^{1 *}$, Barry J Maron², lacopo Olivotto ${ }^{3}$, Gabriele Egidy Assenza ${ }^{3}$, Tammy S Haas², John R Lesser², \\ Christiane Gruner ${ }^{1}$, Andrew Crean ${ }^{1}$, Harry Rakowski ${ }^{1}$, James E Udelson ${ }^{4}$, Ethan J Rowin ${ }^{4}$, Massimo Lombardi ${ }^{3}$, \\ Franco Cecchi ${ }^{3}$, Benedetta Tomberli ${ }^{3}$, Paolo Spirito ${ }^{3}$, Francesco Formisano $^{3}$, Elena Biagini ${ }^{3}$, Claudio Rapezzi $^{3}$, \\ Carlo Nicola De Cecco ${ }^{3}$, Camillo Autore 3 , Susie N Hong ${ }^{5}$, Michael C Gibson ${ }^{5}$, Warren J Manning 5 , \\ Evan Appelbaum ${ }^{5}$, Martin Maron ${ }^{4}$
}

From 18th Annual SCMR Scientific Sessions

Nice, France. 4-7 February 2015

\section{Background}

Extensive fibrosis detected by late gadolinium enhancement (LGE) in contrast enhanced cardiac magnetic resonance (CMR) has recently been identified as a prognostic marker for adverse events in hypertrophic cardiomyopathy (HCM) patients. However, use of CMR in all patients with HCM may be limited by cost and availability. We therefore sought to develop a score based on clinical and imaging variables to predict the probability of extensive LGE, defined by $\geq 15 \%$ of left ventricular (LV) myocardium with LGE.

\section{Methods}

We assessed the relation between clinical and imaging variables with extensive LGE in an international multicenter cohort of $1293 \mathrm{HCM}$ patients. We used logistic regression to construct integer risk weights for independent variables which predict the presence of extensive LGE. These weights were summed for each patient to create a score (LGE-Score) to predict the probability of extensive LGE.

\section{Results}

Extensive LGE was found in 109 of 1293 patients (8.4\%). There were 5 independent predictors for extensive LGE: LV ejection fraction (LVEF) $(\mathrm{p}<0.0001)$, history of nonsustained ventricular tachycardia (NSVT) $(\mathrm{p}<0.0001)$, history of atrial fibrillation $(\mathrm{p}=0.02)$, maximal wall

\footnotetext{
${ }^{1}$ Toronto General Hospital, Toronto, ON, Canada

Full list of author information is available at the end of the article thickness $(\mathrm{p}=0.0001)$, and significant resting LV outflow tract gradient $(\mathrm{LVOT})>30 \mathrm{mmHg}(\mathrm{p}=0.02)$. Their associated additive risk-weights in the LGE-Score (in parentheses) were as follows: LVEF $\geq 70 \%(0), 50-70 \%(+4$ points), $<50 \%$ ( +8 points); history of NSVT ( +3 points); history of atrial fibrillation $(+2$ points); maximal wall thickness $<16.25 \mathrm{~mm}(0), 16.25-19.2 \mathrm{~mm}$ ( +1 points), 19.2$22.9 \mathrm{~mm}$ ( +2 points), $\geq 22.9 \mathrm{~mm}$ ( +3 points); significant resting LVOT gradient ( -2 points). The model has an area under receiver operator curve of 0.794 . Using a cutoff LGE-Score of $\leq+4$ points, the negative predictive value for extensive LGE was $98 \%$.

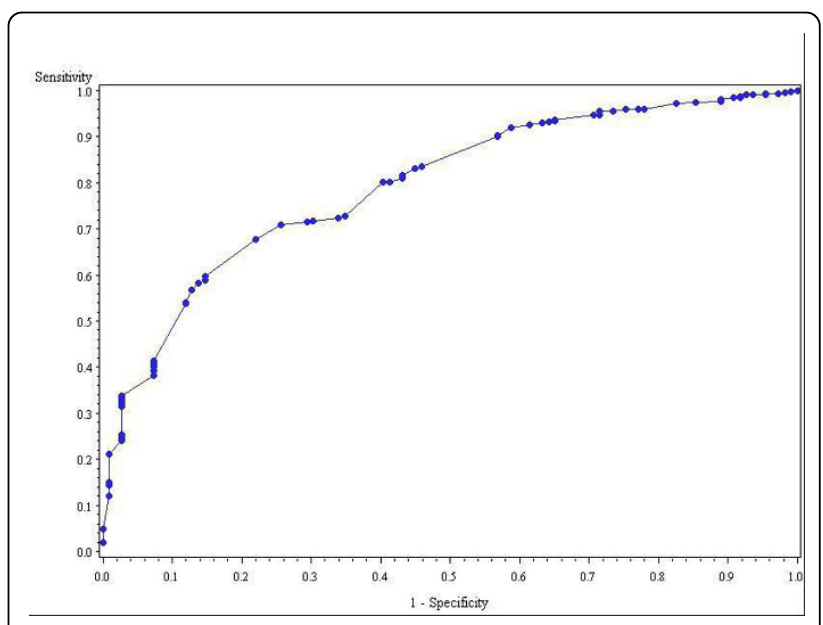

Figure 1 ROC curve for LGE-Score. 


\section{Conclusions}

Extensive LGE (myocardial fibrosis/scarring) identifies HCM patients at significantly increased risk for sudden death events, however CMR is not available to all patients. For those who are unable to undergo CMR imaging, this novel predictive score can be used to identify those HCM patients who are highly unlikely to have extensive myocardial scarring.

\section{Funding}

Nil.

\section{Authors' details}

${ }^{1}$ Toronto General Hospital, Toronto, ON, Canada. ${ }^{2}$ Minneapolis Heart Institute Foundation, Minneapolis, MN, USA. ${ }^{3}$ Azienda Ospedaliera Universitaria Careggi, Florence, Italy. ${ }^{4}$ Tufts Medical Center, Boston, MA, USA. ${ }^{5}$ Beth Israel Deaconess Medical Center, Boston, MA, USA.

Published: 3 February 2015

doi:10.1186/1532-429X-17-S1-Q59

Cite this article as: Chan et al:: Late gadolinium enhancement score

(LGE-Score) for prediction of extensive late gadolinium enhancement in hypertrophic cardiomyopathy. Journal of Cardiovascular Magnetic

Resonance 2015 17(Suppl 1):Q59.

Submit your next manuscript to BioMed Central and take full advantage of:

- Convenient online submission

- Thorough peer review

- No space constraints or color figure charges

- Immediate publication on acceptance

- Inclusion in PubMed, CAS, Scopus and Google Scholar

- Research which is freely available for redistribution

Submit your manuscript at www.biomedcentral.com/submit
C Biomed Central 